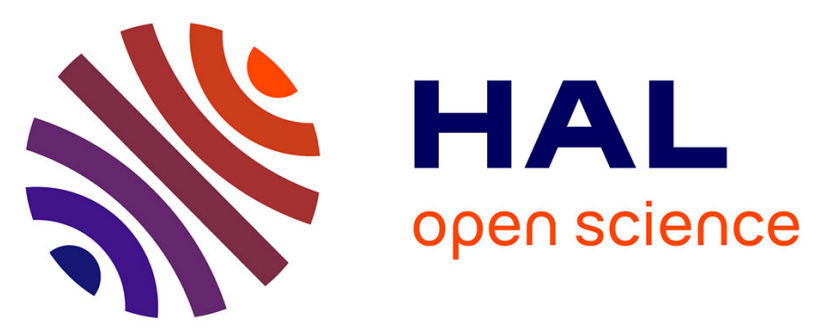

\title{
Land use and the spatial distribution of perfluoroalkyl compounds as measured in the plasma of bottlenose dolphins Tursiops truncatus
}

Jeffrey Adams, Magali Houde, Derek Muir, Todd Speakman, Gregory Bossart, Patricia Fair

\section{To cite this version:}

Jeffrey Adams, Magali Houde, Derek Muir, Todd Speakman, Gregory Bossart, et al.. Land use and the spatial distribution of perfluoroalkyl compounds as measured in the plasma of bottlenose dolphins Tursiops truncatus. Marine Environmental Research, 2008, 66 (4), pp.430. 10.1016/j.marenvres.2008.07.004 . hal-00563043

\section{HAL Id: hal-00563043 https://hal.science/hal-00563043}

Submitted on 4 Feb 2011

HAL is a multi-disciplinary open access archive for the deposit and dissemination of scientific research documents, whether they are published or not. The documents may come from teaching and research institutions in France or abroad, or from public or private research centers.
L'archive ouverte pluridisciplinaire HAL, est destinée au dépôt et à la diffusion de documents scientifiques de niveau recherche, publiés ou non, émanant des établissements d'enseignement et de recherche français ou étrangers, des laboratoires publics ou privés. 


\section{Accepted Manuscript}

Land use and the spatial distribution of perfluoroalkyl compounds as measured in the plasma of bottlenose dolphins Tursiops truncatus

Jeffrey Adams, Magali Houde, Derek Muir, Todd Speakman, Gregory Bossart, Patricia Fair

PII:

S0141-1136(08)00180-3

DOI:

10.1016/j.marenvres.2008.07.004

Reference:

MERE 3270

To appear in:

Marine Environmental Research

Received Date:

19 February 2008

Revised Date:

12 June 2008

Accepted Date:

8 July 2008

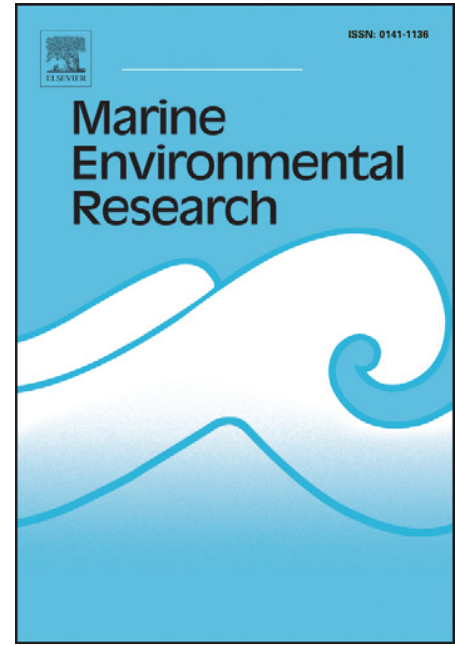

Please cite this article as: Adams, J., Houde, M., Muir, D., Speakman, T., Bossart, G., Fair, P., Land use and the spatial distribution of perfluoroalkyl compounds as measured in the plasma of bottlenose dolphins Tursiops truncatus, Marine Environmental Research (2008), doi: 10.1016/j.marenvres.2008.07.004

This is a PDF file of an unedited manuscript that has been accepted for publication. As a service to our customers we are providing this early version of the manuscript. The manuscript will undergo copyediting, typesetting, and review of the resulting proof before it is published in its final form. Please note that during the production process errors may be discovered which could affect the content, and all legal disclaimers that apply to the journal pertain. 
Title: Land use and the spatial distribution of perfluoroalkyl compounds as measured in the plasma of bottlenose dolphins (Tursiops truncatus)

Authors: Jeffrey Adams**, ${ }^{*}$, Magali Houde ${ }^{2, * *}$, Derek Muir ${ }^{3}$, Todd Speakman ${ }^{1}$, Gregory Bossart $^{4}$, and Patricia Fair ${ }^{1}$

\section{Affiliations:}

${ }^{1}$ Center for Coastal Environmental Health and Biomolecular Research, National Centers for Coastal Ocean Science, National Ocean Service, National Oceanic and Atmospheric Administration, 219 Fort Johnson Road, Charleston, SC 29412, United States

${ }^{2}$ Department of Environmental Biology, University of Guelph, Guelph, Ontario, N1G 2W1, Canada

${ }^{3}$ Aquatic Ecosystem Protection Research Division, Environment Canada, 867 Lakeshore Road, Burlington L7R 4A6 Ontario, Canada

${ }^{4}$ Division of Marine Mammal Research and Conservation, Harbor Branch Oceanographic Institution, 5600 US 1 North, Ft. Pierce, Florida 34946, United States

* Corresponding Author: Tel.: +1 843762 8604, Fax: +1 843762 8700, Email Address: Jeff.Adams@noaa.gov

** Current address: 3686 Rue St-André, Montreal, Qc H2L 3V7 


\title{
ACCEPTED MANUSCRIPT
}

\begin{abstract}
:
The distribution of perfluoroalkyl compounds (PFCs) in the environment is well documented with higher concentrations observed in wildlife located in industrial and urban areas. This study examined the distribution of PFCs in relation to land use using blood samples collected from bottlenose dolphins during capture-release health assessment surveys conducted in Charleston, SC. The study area was partitioned into three subareas (ACW, CHS, and SRE) based upon habitat and land use characteristics. The ACW and CHS subareas are characterized by high degrees of industrial and urban land uses, while the SRE subarea is more residential and characterized by a lower degree of developed land use. Long-term monitoring data from photoidentification surveys were used to group bottlenose dolphins based on their proportions of sightings in the different subareas. Dolphins affiliated with both the ACW and CHS subareas were observed to have significantly higher mean plasma concentrations of perfluorooctane sulfonate (PFOS), perfluorodecanoic acid (PFDA) and perfluoroundecanoic acid (PFUnA) than those affiliated with the SRE subarea. Dolphins affiliated with the ACW subarea were found to have a significantly higher mean plasma concentration of PFUnA than those affiliated with the CHS subarea. Further examination of the distribution of the PFCs revealed positive correlations with developed land uses and negative correlations with wetland/marsh land cover. A positive correlation was also observed between PFUnA and agricultural land use. The variability and scale of the observed contaminant burdens have important implications for the conservation and management of living marine resources and illustrates the importance of long-term monitoring of free-ranging wildlife species.
\end{abstract}

Keywords: perfluoroalkyl compounds, bottlenose dolphin, land use, urbanization, spatial scale, habitat, estuaries, coastal zone 


\section{ACCEPTED MANUSCRIPT}

\section{Introduction:}

Perfluoroalkyl compounds (PFCs) have been used commercially for approximately 50 years; however, their widespread distribution in the environment has just recently become the focus of investigation (Giesy \& Kannan, 2001). PFCs are used in the manufacture of a number of consumer products due to their surfactant properties. Examples of products include non-stick kitchenware, furniture, clothing, paper products, paints, polishes, insecticides, herbicides, cosmetics, food packaging materials, adhesives, and fire fighting foams (Hekster et al., 2002; Key et al., 1997; Organisation for Economic Co-operation and Development, 2007). Because many PFCs are resistant to degradation, they are persistent in the environment (Key et al., 1997; United Nations Environment Programme, 2006). One of the more persistent, widely-distributed and studied PFCs is perfluorooctane sulfonate (PFOS). The occurrence of PFOS in the environment is primarily due to the chemical and/or biochemical breakdown of perfluorooctane sulfonyl fluoride (PFOSF)-based PFCs (United Nations Environment Programme, 2006). Adverse health effects (Lau et al., 2007), occurrence in remote regions (Kannan et al., 2001), and intense scrutiny by the United States Environmental Protection Agency (United States Environmental Protection Agency, 2000) prompted 3M Company, the largest manufacturer of PFOSF-based PFCs, to phase out their direct manufacture. The decline in the production of PFOSF-based PFCs has coincided with a rise in the manufacture and use of fluorotelomer alcohols (FTOHs) and other telomer-based PFCs (Wania, 2007). Because FTOHs share similar chemical properties to PFOSF-based products, they are often used as precursor compounds for many of the same applications (Kissa, 1994; Organisation for Economic Co-operation and Development, 2007). Degradation of FTOHs yields perfluorocarboxylic acids (PFCAs), which, like PFOS, are 


\section{ACCEPTED MANUSCRIPT}

toxic, persistent in the environment, and widely-distributed (Houde et al., 2006b; Lau et al., 2007). PFOS and PFCAs have been detected globally in human blood from both developed and developing countries(Kannan et al., 2004).

The global distribution of PFCs in the marine environment is well documented. Unlike polychlorinated biphenyls (PCBs) and organochlorine pesticides, PFCs are detected at higher concentrations in the water column relative to sediment (Lau et al., 2007; Nakata et al., 2006). They are present in coastal and offshore oceanic waters of both urban/industrial and remote areas (Yamashita et al., 2005; Yamashita et al., 2007). Their detection in seawater and marine sediment in remote marine environments is believed to be a result of atmospheric and/or oceanic transport of both direct emissions and volatile precursor compounds (Wania, 2007; Yamashita et al., 2007). In marine biota, PFCs have been observed at various trophic levels. They have been detected in benthic organisms, forage and predator fish species, and apex predators such as marine mammals (Houde et al., 2006a; Nakata et al., 2006). In addition to being detected at various trophic levels, a number of studies have also demonstrated their biomagnification potential (Houde et al., 2006b; Kannan et al., 2001; Martin et al., 2004; Nakata et al., 2006). As such, the risk of accumulating elevated concentrations of PFCs is greater for apex predators such as marine mammals.

PFOS and PFCA concentrations detected in the plasma of bottlenose dolphins sampled in Charleston, SC (2003-2004) represent some of the highest concentrations reported in marine mammals (Houde et al., 2006b; Houde et al., 2005). Charleston, SC is centrally located within the southeast region of the United States. With a population growth rate of $58 \%$ between 1980 and 2003, the southeast region is the fastest growing region in the United States (Crosset et al., 2004). Much of the growth in the region is occurring in coastal 


\section{ACCEPTED MANUSCRIPT}

counties, leading to increased pressures on coastal resources. Charleston, SC ranks among the top 100 fastest-growing metropolitan areas (United States Census Bureau, 2007). Population density and the degree of urbanization are quite variable along the shoreline of the coastal and estuarine waters in and around Charleston, SC. Higher concentrations of PFCs in marine environments have often been associated with proximity to urban/industrial areas (Giesy \& Kannan, 2001; Keller et al., 2005; Kim \& Kannan, 2007; So et al., 2004; Taniyasu et al., 2003; Yamashita et al., 2005). The objective of this study was to examine the impact of land use on the concentrations of PFOS and PFCAs detected in the plasma of bottlenose dolphins sampled in the estuarine waters in and around Charleston, SC. Specifically, we were interested in examining whether differences in PFC concentrations due to land use could be observed on a much more local scale than previously reported.

\section{Materials and Methods:}

\subsection{Study Area:}

The study area is located in Charleston, SC $\left(32^{\circ} 46^{\prime} 48^{\prime \prime} \mathrm{N}, 79^{\circ} 55^{\prime} 48^{\prime \prime} \mathrm{W}\right)$ and includes the Charleston Harbor, as well as portions of the main channels and creeks of the Ashley River, Cooper River, Wando River and the Stono River Estuary (Figure 1). For the purposes of the analyses described herein, the study area was partitioned into the following three subareas based on habitat type and degree of developed (urban/industrial) land use: Ashley, Cooper and Wando Rivers (ACW), Charleston Harbor (CHS), and the Stono River Estuary (SRE). The ACW and CHS subareas are located in the Charleston Harbor estuary and are characterized by a high degree of developed land uses. The SRE subarea is located approximately $20 \mathrm{~km}$ south of the Charleston Harbor Estuary and is characterized by a much lower degree of development. The CHS subarea is also characterized by a prevalence of open 


\section{ACCEPTED MANUSCRIPT}

water habitat, while the ACW and SRE subareas are dominated by river channels and tidal creeks.

\subsection{Sample Collection and Analysis}

Health assessments of coastal bottlenose dolphin (Tursiops truncatus) populations are being conducted at multiple sites along the southeast coast of the United States in order to investigate trends in health status, as well as chemical and biological toxicant exposure. In the Charleston, SC study area, a total of 84 bottlenose dolphins were captured, sampled and released during the summer months of 2003-2005 as part of a collaborative effort between the National Ocean Service's Center for Coastal Environmental Health and Biomolecular Research and Harbor Branch Oceanographic Institution (Fair et al., 2006). Blood samples were collected from the fluke vein of 83 of the captured individuals and analyzed for concentrations of PFOS and the following four PFCAs: perfluorooctanoic acid (PFOA), perfluorononanoic acid (PFNA), perfluorodecanoic acid (PFDA), and perfluoroundecanoic acid (PFUnA). Sample extraction, analysis, and quality control procedures are detailed in Houde et al. (2005).

\subsection{Subarea Affiliations}

An understanding of the spatial distributions of bottlenose dolphins is imperative for the examination of relationships between environmental factors and health. Because the ranging characteristics of bottlenose dolphins can be quite variable in size and by season, the capture locations of the individuals sampled in the study area may not be indicative of their core area of use. A common approach used to monitor marine mammals for the purposes of determining area usage is through long-term photo-identification research (Ballance, 1992; Maze \& Würsig, 1999; Wilson et al., 1997; Zolman, 2002). 


\section{ACCEPTED MANUSCRIPT}

During photo-identification surveys, a research vessel proceeds along a designated survey route. Upon sighting an individual or group of dolphins, data pertaining to the location (latitude and longitude), dolphin/group behavior, and environmental conditions are recorded. Digital photographs of individual dorsal fins obtained and natural markings on the dorsal fins are used to distinguish individuals. Digital photographs of individuals with distinctively marked fins are subsequently cataloged as new individuals or matched to previously sighted catalog entries.

Photo-identification research has been ongoing in the study area for over 10 years, with the goal of determining the resident status and population size of bottlenose dolphins. Prior to 2004, the survey effort in the different subareas was both spatially and temporally variable. Beginning in 2004, survey routes, effort and protocols were standardized. In the study area, survey effort was standardized to include one survey per month in each of the subareas, except for the months of January, April, July and October, in which two surveys in each subarea were conducted. To ensure equal survey effort across subareas and standardized protocols, only data collected in photo-identification surveys conducted after January 2004 were used to calculate the relative sighting proportions.

To examine PFC concentrations among sampled individuals exhibiting fidelity to the different subareas, relative sighting proportions (SP) in the different subareas were calculated for each dolphin using the following equation:

$$
\mathrm{SP}_{\mathrm{i}}=\frac{\mathrm{n}_{\mathrm{i}}}{\sum_{\mathrm{j}=1}^{\mathrm{N}} \mathrm{n}_{\mathrm{j}}}
$$

where,

$n_{i}=$ number of times individual was sighted in subarea $i$, and 


\section{ACCEPTED MANUSCRIPT}

$N=$ number of subareas.

At the time of this analysis, two years of photo-identification data were available, which included a total of 32 photo-identification surveys for each subarea. To account for potential immigration and emigration effects, survey counts used to calculate relative sighting proportions included only surveys that were conducted between an individual's first and last recorded sighting in the two year period. For the purposes of this study, individuals with a $\mathrm{SP} \geq 0.5$ for a particular subarea were classified as affiliated with the subarea.

\subsection{Land Use Associations}

Land use associations for sampled individuals were derived via GIS analysis using Environmental Systems Research Institute, Inc.'s (ESRI) ArcGIS 9.2 software. Buffer polygons with radii of $1000 \mathrm{~m}$ were created using every sighting location of each sampled individual. The buffer polygons were then overlayed on the Zone 58 Land Cover Layer of the 2001 National Land Cover Database (NLCD), to extract the land cover classes contained in the buffer polygons (Figure 2). Table 1 contains the 15 land use classes contained in the NLCD land cover dataset. The amount of area in each of the land cover classes found in the sighting location buffer polygons was then summarized by individual and further aggregated into classes found in the Anderson Level I Land Use classification scheme (Anderson et al., 1976). These land use classes included developed, forested, agriculture, and wetland (Table 1). Ratios of these land use classes present in the sighting location buffer polygons of each sampled individual were computed.

\subsection{Statistical Analyses}

To examine the relationship between PFC concentrations and subarea affiliations, one-way analysis of variance (ANOVA) procedures were performed. Only dolphins with a 


\section{ACCEPTED MANUSCRIPT}

subarea affiliation were included in the ANOVA analyses. To meet assumptions of equal variance and normality, PFC concentrations were log transformed. Subarea affiliation served as the independent variable and pairwise comparisons were conducted using Fisher's LSD Multiple Comparison Test. Nonmetric Multidimensional Scaling (NMDS) was also performed using PFOS and the 4 PFCAs as inputs. PFC concentrations were square-root transformed and submitted to Wisconsin double standardization to improve the quality of the ordination. Bray-Curtis similarities were calculated and a two-dimensional ordination plot created to examine the spatial variability of PFC concentrations with respect to subarea affiliation and land uses found in the sampled individuals' sighting location buffer polygons. As with the ANOVAs, only dolphins with a subarea affiliation were included in the NMDS analysis. To further examine the association between PFC concentrations and land uses found in the sampled individuals' sighting location buffer polygons, Spearman rank correlation coefficients were computed. All sampled individuals $(n=83)$, regardless of subarea fidelity, were included in the correlation analysis.

\section{Results:}

\subsection{Subarea Affiliations}

Of the 83 bottlenose dolphins with PFC plasma data, 62 had SP values $\geq 0.5$ for the ACW ( $n=12)$, CHS $(n=37)$, or SRE $(n=13)$ subareas. The average number of sightings for the 62 dolphins with subarea affiliations was 10.9 , with a minimum and maximum sighting count of 4 and 21, respectively. Of the 62 dolphins with subarea affiliations, 60 were sighted in 3 or more seasons and 46 were sighted in all four seasons. Age data, via analysis of post-natal dentine layers in extracted teeth, were available for 46 of the 62 subarea-affiliated dolphins. An ANOVA indicated that age differences between the ACW ( $\bar{x}=12.8, n=9)$, CHS $(\bar{x}=16.4$, 


\section{ACCEPTED MANUSCRIPT}

$\mathrm{n}=25)$ and $\operatorname{SRE}(\overline{\mathrm{x}}=12.2, \mathrm{n}=12)$ dolphins were not significant $(\mathrm{F}(2,43)=0.88, \mathrm{p}=0.421)$. A G-

test of independence was conducted to examine gender composition for the three groups of subarea affiliated dolphins. Results indicated that gender and sub-area affiliation were independent $(\mathrm{G}=1.56, \mathrm{p}=0.46)$.

The SRE dolphins possessed the highest average SP value (0.85), suggesting high site fidelity. Only 3 of the 13 SRE dolphins had sightings outside of the SRE subareas, all of which were in the CHS subarea. The average SP values for the ACW and CHS dolphins were 0.70 and 0.71 , respectively. Of the $12 \mathrm{ACW}$ affiliated dolphins, 11 also had sightings in the CHS subarea. No SRE sightings were observed for the ACW dolphins. Of the 37 CHS dolphins, 14 had sightings in the ACW subarea and 9 had sightings in the SRE subarea.

\subsection{PFC Concentrations and Subarea Affiliations:}

Mean PFC concentrations for all dolphins sampled in Charleston, SC during 2003 and 2004 have been previously published (Houde et al., 2006b; Houde et al., 2005). Of the 5 PFCs analyzed for the subarea-affiliated dolphins sampled in 2003-2005, PFOS was detected at the highest concentrations, with geometric mean concentrations ranging from $771 \mathrm{ng} / \mathrm{g} \mathrm{ww}$ (SRE) to $1380 \mathrm{ng} / \mathrm{g}$ ww (ACW). Individual concentrations of PFOS ranged from $317 \mathrm{ng} / \mathrm{g}$ ww to $6260 \mathrm{ng} / \mathrm{g}$ ww. Of the 4 PFCAs analyzed, PFDA was detected at the highest concentrations, with geometric mean concentrations ranging from $88.4 \mathrm{ng} / \mathrm{g} \mathrm{ww}$ (SRE) to 194 ng/g ww (ACW). Plasma PFC concentration summary statistics for subarea-affiliated dolphins are presented in Table 2.

The ANOVAs $(\alpha=0.05)$ indicated that mean PFOS $(F(2,59)=4.31, p=0.018)$, PFDA $(\mathrm{F}(2,59)=5.03, \mathrm{p}=0.010), \operatorname{PFUnA}(\mathrm{F}(2,59)=7.07, \mathrm{p}=0.002)$, and $\sum \mathrm{PFCs}(\mathrm{F}(2,59)=4.10$, $\mathrm{p}=0.021)$ plasma concentrations varied significantly $(\alpha=0.05)$ as a function of subarea 


\section{ACCEPTED MANUSCRIPT}

affiliation. Mean PFOA $(\mathrm{F}(2,59)=0.47, \mathrm{p}=0.626)$ and $\operatorname{PFNA}(\mathrm{F}(2,59)=0.50, \mathrm{p}=0.610)$ plasma concentrations were not found to vary significantly as a function of subarea affiliation. Posthoc analyses $(\alpha=0.05)$ indicated that individuals with a SRE area affiliation had a significantly lower mean plasma PFOS concentration than those affiliated with the ACW $(\mathrm{p}=0.020)$ and CHS $(\mathrm{p}=0.007)$ subareas. A significant difference in mean plasma PFOS concentration was not detected between the ACW and CHS affiliated dolphins. A similar pattern was observed for PFDA and $\sum$ PFCs. Individuals with a SRE area affiliation had a significantly lower mean plasma PFDA and $\sum$ PFCs concentrations than those affiliated with the ACW ( $\mathrm{p}=0.004$ and $\mathrm{p}=0.015$, respectively) and CHS $(\mathrm{p}=0.011$ and $\mathrm{p}=0.012$, respectively) subareas, while no significant difference was detected between the ACW and CHS affiliated dolphins. Significant differences in mean plasma PFUnA concentrations were detected between each of the three groups. Individuals with a SRE area affiliation had a significantly lower mean plasma PFUnA concentration than those affiliated with the ACW $(p=0.000)$ and CHS ( $\mathrm{p}=0.048)$ subareas, and individuals with a CHS area affiliation had a significantly lower mean plasma PFUnA concentration than those affiliated with the ACW $(p=0.013)$ subarea.

The result of the NMDS ordination is presented in Figure 4. The CHS dolphins are scattered through the ordination plot, however, good separation exists between the ACW and SRE dolphins. Bubbles representing $\sum$ PFCs highlight differences in PFC concentrations between the ACW and SRE dolphins. A single outlier was graphically identified by both box and scatter plots, but retained in the ANOVA, NMDS, and correlation analyses. This individual is depicted with a faded $\sum$ PFCs bubble in the ordination plot.

\subsection{PFC Concentrations and Land Use:}




\section{ACCEPTED MANUSCRIPT}

Vectors representing land use classes associated with the sampled dolphins, as described in section 2.4, were added to the ordination plot (Figure 4). Arrows associated with the different vectors point in the direction of most rapid change for the specific land use gradient and the length of the vector is proportional to the correlation between the ordination and the land use category. The fitted vectors for developed and wetland land use classes were both found to be significant $(\mathrm{p}<0.001)$. The fitted vectors illustrate that ACW dolphins, which had the highest mean concentration for 4 of the 5 PFCs analyzed (Table 2), are more associated with developed land use classes than CHS and SRE dolphins. SRE dolphins, which had the lowest mean concentrations for 4 of the 5 PFCs analyzed (Table 2), are shown to be more associated the wetland land use class than ACW and CHS dolphins. The wide scatter of the CHS dolphins relative to the fitted vectors indicates associations with a mixture of land use classes.

Table 3 displays the Spearman rank correlation coefficients for PFC concentrations and land use. Significant negative correlations $(\alpha=0.05)$ were observed between the wetland (marsh) land use class and PFOS $(\rho=-0.219, p=0.047), \operatorname{PFDA}(\rho=-0.224, p=0.042)$, and PFUnA $(\rho=-0.312, p=0.004)$ plasma concentrations. Significant positive correlations $(\alpha=0.05)$ were observed between PFUnA plasma concentrations and the developed $(\rho=0.315$, $\mathrm{p}=0.004)$ and agriculture $(\rho=0.292, \mathrm{p}=0.007)$ land use classes. Positive correlations were also observed between the developed land use class and PFOS $(\rho=0.203, p=0.066)$ and PFDA $(\rho=0.197, p=0.074)$ concentrations.

\section{Discussion}

The location of the sampling media is a fundamental component of analyses correlating land use with environmental contaminants. While sediment and water samples are 


\section{ACCEPTED MANUSCRIPT}

stationary and can be characterized using a single location, bottlenose dolphins are freeranging and represent a more challenging medium for examining spatial relationships between land use and environmental contaminants. The use of existing home range analysis techniques, which were designed primarily for use with terrestrial species, is often inappropriate for marine mammal species. This is especially true for marine mammal species utilizing complex estuarine systems, where many barriers to movement exist. As such, we chose to partition the Charleston, SC study area into three subareas based on habitat type, land use characteristics, and usage patterns observed during bottlenose dolphin field research. Locations for individual dolphins were characterized based on their proportion of sightings in the different subareas. Discretizing the location data did reduce the precision of the data, but the results of the analyses still identified a link between land use and PFC concentrations.

The relationships between subarea affiliations and PFC concentrations were examined using both one-way ANOVAs and NMDS. For the one-way ANOVAs, each of the five compounds and $\sum$ PFCs were examined separately with respect to subarea affiliation. Significant differences were found for $\sum$ PFCs and PFOS, PFDA, and PFUnA. Post-hoc procedures indicated that ACW and CHS dolphins had significantly higher PFOS, PFDA, PFUnA, and $\sum$ PFCs concentrations than those affiliated with the SRE subarea. Significant differences between ACW and CHS dolphins were found only for PFUnA concentrations. A similar pattern can be seen in the ordination plot (Figure 4) from the NMDS analysis, which incorporated all 5 compounds using a non-parametric multivariate approach. Although NMDS is a technique commonly used to examine community structure, it has also been used to analyze the spatial variability of environmental contaminants in sediments (Moon et al., 2007). In the resulting ordination plot, good separation exists between the ACW and SRE 


\section{ACCEPTED MANUSCRIPT}

dolphins, while CHS dolphins are scattered throughout. No separation was anticipated between the ACW and CHS dolphins due to the close proximity of the subareas and the high degree of mixed area usage. The lack of separation between the CHS and SRE dolphins is, however, at odds with the results of the one-way ANOVAs, which indicate significant differences between the CHS and SRE dolphins for $\sum$ PFCs and PFOS, PFDA, and PFUnA. While differences most likely exist between the CHS and SRE dolphins for some of the compounds measured, the ordination plot most likely represents a more accurate depiction of the PFC burden, as a whole, with respect to subarea affiliation. The stress value for the twodimensional ordination by NMDS was 0.15 . Low stress values $(<0.05)$ are desired, but stress values $<0.2$ can still provide a useful two-dimensional picture (Clarke, 1993). Given the results of the ANOVAs, the ordination plot is considered to be a useful summary of the spatial variability.

An examination of land cover within $1 \mathrm{~km}$ of the shorelines of the three different subareas yielded the following percentages of developed land use: ACW=22\%, CHS $=19 \%$ and $\mathrm{SRE}=3 \%$. The fitted vectors in Figure 4 suggest that dolphins affiliated with the ACW and CHS subareas appear to be more associated with developed land uses than the SRE affiliated dolphins. Of the three groups, the ACW and SRE dolphins represent the extremes with respect to developed land use, and good separation exists between the two in the ordination plot. The results of the ANOVAs along with the ordination plot indicate a positive correlation between developed land uses and PFC concentrations.

A positive correlation between developed land uses and PFC concentrations is also suggested by the Spearman rank correlation matrix. A significant positive correlation exists between PFUnA concentrations in the plasma of sampled bottlenose dolphins and the amount 


\section{ACCEPTED MANUSCRIPT}

of developed land use found in their buffered sighting locations. Similar results, though not significant at $\alpha=0.05$, were observed for PFOS and PFDA. These correlations, though weak, reinforce results observed in the ANOVAs and NMDS. Dolphins affiliated with subareas characterized by higher amounts of developed land uses were found to have higher concentrations of PFCs. PFUnA was also found to be positively correlated with the amount of agricultural land use found in buffered sighting locations. PFCs, such as perfluoroalkyl phosphonates, are used in crop protection agents such as herbicides, fungicides and insecticides as surfactants to ensure uniform wetting of leaf surfaces and, consequently, better absorption of active ingredients. Quite often, "inert" ingredients such as surfactants constitute a significant proportion of the product. It is possible that PFCs in locally used crop protection agents are entering the estuarine waters via nonpoint source agricultural runoff. However, from the analysis of PFC concentrations and subarea affiliations, it was revealed that ACW affiliated dolphins possess significantly higher concentrations of PFUnA. While the sighting buffers of ACW affiliated dolphins possess the highest average proportion of agricultural land uses (Figure 3), it is possible that the positive correlation with agricultural land use is confounded by the fact that the sighting buffers of ACW affiliated dolphins also possess the highest average proportion of developed land.

Significant negative correlations were observed between the amount of wetland found in buffered sighting locations and PFOS, PFDA, and PFUnA concentrations. The wetland land use category for the Charleston study site consists mainly of estuarine salt marsh. Salt marshes represent a land use with little to no anthropogenic impact, provide a buffer between aquatic life and developed land uses and function as a natural filter for certain chemicals and 


\section{ACCEPTED MANUSCRIPT}

pathogens. This supports the significantly lower concentrations observed in dolphins affiliated with the SRE subarea, which is dominated by salt marsh.

The results of the analyses conducted herein indicate that spatial differences in PFC concentrations can be detected in biota on a much more local scale than previously reported. Similar fine-scale geographic differences in persistent organic pollutants have recently been reported for bottlenose dolphins sampled in Biscayne Bay, FL (Litz et al., 2007). The results also lend statistical support to previous research observations of higher PFC concentrations in biotic samples from more industrial and urban areas (Giesy \& Kannan, 2001; Keller et al., 2005; So et al., 2004; Taniyasu et al., 2003; Yamashita et al., 2005).

While a relationship between land use and concentrations of PFCs were detected, significance levels, especially those associated with the Spearman rank correlations, and the scatter observed in the ordination plot suggest a somewhat weaker relationship than expected. As was mentioned previously, analyses using free-ranging species such as bottlenose dolphin as sampling media for examining spatial relationships between land uses and environmental contaminants are more challenging than those using stationary media such as sediment and water samples. The weakness of the observed relationships could be datarelated, in that most of the dolphins analyzed were associated with the more urban ACW and CHS subareas. As such, the gradient of developed land use was skewed and may have impacted the robustness of the analyses. Another data-related factor potentially contributing to the strength of the observed relationship might be the use of a limited number of sightings to represent the entirety of an individual dolphin's range. Because of the relatively closed nature of the study area and the high fidelity of the sampled dolphins to the subareas, it is 


\section{ACCEPTED MANUSCRIPT}

believed that the sighting histories provide reasonable representations of range and habitat usage. Additional sighting information, however, would lead to a more robust analysis.

Model-related factors might also be contributing to the strength of the observed relationships. Nonpoint and point sources from land uses beyond the reach of the sighting buffers most likely play an important role in the contribution of contaminants into the system. The near shore land use information obtained via the buffer analysis may not provide a complete picture of the land use patterns impacting the estuarine system. Additionally, correlations between PFC concentrations in the sampled bottlenose dolphins and developed land use may be more indicative of the role of nonpoint sources.

Point sources such as waste water treatment outfalls may also play a role. In October of 2004, water and sediment samples were collected in the study area and analyzed for the presence of PFCs. In addition, composite water samples were obtained from four water treatment facilities with outfalls located within the Charleston Harbor. Houde et al. (2006b) presents summary statistics for the PFCs detected in the water, sediment and effluent samples. As observed in previous research (Nakata et al., 2006), PFOS was found to partition into the water column over the sediment. The highest PFOS concentrations for the water samples collected in situ were detected in the samples from the Charleston Harbor and the Ashley and Cooper Rivers, while the three lowest concentrations were observed in the samples collected in the Stono River Estuary. Concentrations measured in water samples from the effluent of the four water treatment facilities exceeded concentrations detected in all of the in situ water samples. Similar patterns were observed for most of the PFCAs. The four municipal water outfalls located in the study area are all situated in the CHS subarea. Small sample sizes and large variances precluded a robust statistical analysis of the water samples, 


\section{ACCEPTED MANUSCRIPT}

but the observed concentrations suggest municipal water outfalls most likely play a role in the observed distribution of PFCs in the study area.

Another model-related factor contributing to the strength of the observed relationships may be related to the ranging characteristics of prey species. Houde et al. (2006b) observed food web biomagnification of PFCs in the Charleston study area. Trophic transfer most likely represents one of the more significant inputs of PFCs into higher order species such as bottlenose dolphins. As such, the ranging characteristics of prey species become equally, if not more important than the ranging characteristics of the sampled individuals when correlating PFC concentrations with land use and cover characteristics. The current model operates under the assumption that the ranges of the sampled bottlenose dolphins and their prey species overlap. It is quite probable that this is not always the case, and this may be one of the major contributors to the weakness of the observed land use correlations.

\section{Conclusions}

Coastal regions are the most densely populated and rapidly growing regions in the United States. From 1973 to 1994, a 40\% population growth rate in Charleston, SC was coupled with a $250 \%$ increase in urban area (Beach, 2002). In estuarine systems such as Charleston, SC, population growth is accompanied by an increased input of contaminants from both point sources, such as municipal and industrial outfalls, and nonpoint sources associated with changing land use patterns. Understanding the impacts that population growth and land use can have on marine and estuarine habitat is of great importance. While existing studies have noted higher PFC concentrations in wildlife located in industrial and urban areas, to our knowledge, this study represents the first attempt to apply statistical 


\section{ACCEPTED MANUSCRIPT}

analyses to such observations. The results of our analyses indicate that a relationship does exist between land use and the spatial distribution of PFC concentrations in bottlenose dolphin. Dolphins frequenting areas characterized by relatively higher degrees of developed land uses were found to have higher concentrations of PFCs. In addition, we have demonstrated that the impact of urbanization on the distribution of PFCs in the environment can manifest itself on a much more local scale than previously observed. This issue of localized impacts has important implications for similar studies investigating within and across site contaminant concentrations in free-ranging wildlife species such as bottlenose dolphins. For sites characterized by multiple habitat (e.g. open water, river channels, tidal creeks, etc.) and land cover types, characterizing contaminant burdens by aggregating all sampled individuals may understate the magnitude of exposures and associated risks. This study illustrates the importance of long-term monitoring data and habitat-based analyses for the accurate assessment of risks posed to free-ranging wildlife species. 


\section{ACCEPTED MANUSCRIPT}

\section{Disclaimer}

This publication does not constitute an endorsement of any commercial product or intend to be an opinion beyond scientific or other results obtained by the National Oceanic and Atmospheric Administration (NOAA). No reference shall be made to NOAA, or this

publication furnished by NOAA, in any advertising or sales promotion which would indicate or imply that NOAA recommends or endorses any proprietary product mentioned herein, or which has as its purpose an interest to cause the advertised product to be used or purchased because of this publication.

\section{Acknowledgements}

We would like to thank the numerous researchers who participated in the capture-and-release field study and photo-identification research in Charleston, SC. We are especially grateful to Eric Zolman, Dr. Forrest Townsend, Larry Fulford, Larry Hansen, and all of the NOAA and HBOI staff and volunteers who provided their expertise. Thanks are also extended to the following reviewers: Dr. Thomas Greig, Mr. Wayne McFee, and Dr. Lori Schwacke. The capture and release field study from which the blood samples were collected was conducted under National Marine Fisheries Permit No. 998-1678-00, issued to Gregory Bossart, V.M.D., Ph.D. of Harbor Branch Oceanographic Institution in March 2003. This study was supported through NOAA/NCCOS/CCEHBR and NOAA Fisheries Marine Mammal Health and Stranding Response Program. 


\section{Figure Captions:}

Figure 1. Map depicting location of and land uses (see Table 1 for land use symbology) in Charleston, SC study area and subareas

Figure 2. Map highlighting land use classes (see Table 1 for land use symbology) found in $1 \mathrm{~km}$ sighting location buffers $(\mathrm{n}=18)$ for a bottlenose dolphin included in analyses

Figure 3. Average proportion of land use classes found in $1 \mathrm{~km}$ sighting location buffers for subarea-affiliated dolphins

Figure 4. NMDS ordination plot of PFC concentrations in bottlenose dolphins from Charleston, SC, including land use vectors, subarea affiliations (point symbol), and $\sum$ PFCs bubbles (ACW and SRE only) 


\section{Tables:}

Table 1. Land use classes and symbology used in analyses and figures

\begin{tabular}{|c|c|c|c|}
\hline \multicolumn{2}{|c|}{ Map Symbol } & \multirow[b]{2}{*}{ NLCD Land Cover } & \multirow[b]{2}{*}{ Correlation Analysis Land Use } \\
\hline Foreground $^{1}$ & Background $^{2}$ & & \\
\hline & 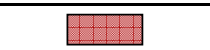 & Developed - High Intensity & \multirow{4}{*}{ Developed } \\
\hline & $\square$ & Developed - Medium Intensity & \\
\hline & $\square$ & Developed - Low Intensity & \\
\hline & $\square$ & Developed - Open Space & \\
\hline & $\square$ & Deciduous Forest & \multirow{3}{*}{ Forested } \\
\hline & E & Evergreen Forest & \\
\hline & $\square$ & Mixed Forests & \\
\hline & Q & Cultivated Crops & \multirow{2}{*}{ Agriculture } \\
\hline & $\square$ & Pasture/Hay & \\
\hline & $\square$ & Emergent Herbaceous Wetlands & \multirow{2}{*}{ Wetland } \\
\hline & $\square$ & Woody Wetlands & \\
\hline & $\square$ & Open Water & \multirow{4}{*}{ N/A } \\
\hline & $\square$ & Barren Land (Rock/Sand/Clay) & \\
\hline & $\square$ & Shrub/Scrub & \\
\hline & \begin{tabular}{|l|l} 
\\
\end{tabular} & Grassland/Herbaceous & \\
\hline
\end{tabular}

${ }^{1}$ symbology used to depict NLCD land use classes within $1 \mathrm{~km}$ sighting location buffers in Figure 2

${ }^{2}$ symbology used to depict background NLCD land use classes found in Figures 1 and 2 


\section{ACCEPTED MANUSCRIPT}

Table 2. Plasma PFC concentration (ng/g wet weight) statistics for subarea-affiliated ( $\mathrm{SP} \geq 0.5$ ) bottlenose dolphins

\begin{tabular}{|c|c|c|c|c|c|c|}
\hline \multirow{2}{*}{ PFC } & \multirow{2}{*}{ Subarea } & \multirow{2}{*}{$\mathbf{n}$} & \multirow{2}{*}{$\operatorname{Mean}^{1}$} & \multicolumn{2}{|c|}{ 95\% Confidence Limit ${ }^{1}$} & \multirow{2}{*}{ Different From ${ }^{2}$} \\
\hline & & & & Lower & Upper & \\
\hline \multirow{3}{*}{ PFOS } & $\mathrm{ACW}$ & 12 & 1380 & 972 & 1960 & SRE \\
\hline & CHS & 37 & 1330 & 1090 & 1630 & SRE \\
\hline & SRE & 13 & 771 & 520 & 1140 & ACW,CHS \\
\hline \multirow{3}{*}{ PFOA } & $\mathrm{ACW}$ & 12 & 25.7 & 9.81 & 67.2 & \\
\hline & CHS & 37 & 36.2 & 25.3 & 51.8 & \\
\hline & SRE & 13 & 36.6 & 24.1 & 55.5 & s \\
\hline \multirow{3}{*}{ PFDA } & $\mathrm{ACW}$ & 12 & 194 & 146 & 257 & SRE \\
\hline & CHS & 37 & 154 & 120 & 198 & SRE \\
\hline & SRE & 13 & 88.4 & 65.1 & 120 & $\mathrm{ACW}, \mathrm{CHS}$ \\
\hline \multirow{3}{*}{ PFNA } & $\mathrm{ACW}$ & 12 & 78.4 & 54.8 & 112 & \\
\hline & CHS & 37 & 70.3 & 53.0 & 93.2 & \\
\hline & SRE & 13 & 58.0 & 37.7 & 89.3 & \\
\hline \multirow{3}{*}{ PFUnA } & $\mathrm{ACW}$ & 12 & 143 & 94.5 & 216 & CHS,SRE \\
\hline & CHS & 37 & 73.6 & 55.5 & 97.7 & ACW,SRE \\
\hline & SRE & 13 & 44.4 & 29.9 & 65.8 & ACW,CHS \\
\hline \multirow{3}{*}{$\sum \mathrm{PFCs}$} & $\mathrm{ACW}$ & 12 & 1880 & 1360 & 2590 & SRE \\
\hline & CHS & 37 & 1710 & 1380 & 2100 & SRE \\
\hline & SRE & 13 & 1030 & 722 & 1470 & $\mathrm{ACW}, \mathrm{CHS}$ \\
\hline
\end{tabular}

${ }^{1}$ geometric means and 95\% confidence limits are reported

${ }^{2}$ Fisher's LSD Multiple-Comparison Test $(\alpha=0.05)$ 


\section{ACCEPTED MANUSCRIPT}

Table 3. Spearman correlation coefficients measuring association between PFC concentrations measured in plasma and land use classes extracted using $1 \mathrm{~km}$ sighting location buffers

\begin{tabular}{ccccc}
\hline & \multicolumn{4}{c}{ Land Use Class } \\
\cline { 2 - 5 } & Developed & Forested & Agriculture & Wetland \\
\hline PFOS & 0.203 & -0.109 & 0.065 & $-0.219^{*}$ \\
p-value & 0.066 & 0.328 & 0.557 & 0.047 \\
\hline PFOA & -0.086 & 0.000 & 0.054 & 0.081 \\
p-value & 0.439 & 0.996 & 0.630 & 0.466 \\
\hline PFDA & 0.197 & 0.050 & 0.086 & $0.224^{*}$ \\
p-value & 0.074 & 0.649 & 0.439 & -0.042 \\
\hline PFNA & 0.083 & 0.049 & 0.233 & 0.574 \\
$p$-value & 0.454 & 0.658 & $0.292 *$ & $-0.312 *$ \\
PFUnA & $0.315^{*}$ & 0.162 & 0.007 & 0.004 \\
\hline -value & 0.004 & & &
\end{tabular}

*significant $(\alpha=0.05)$ 


\section{References:}

Anderson, J. R., Hardy, E. E., Roach, J. T., Witmer, R. E., 1976. A land use and land cover classification system for use with remote sensor data. U.S. Geological Survey, U.S. Geological Survey Professional Paper 964, Washington, DC, 28 pp.

Ballance, L. T., 1992. Habitat use patterns and ranges of the bottlenose dolphin (Tursiops truncatus) in the Gulf of California, Mexico. Marine Mammal Science 8, 262-274.

Beach, D., 2002. Coastal sprawl-the effects of urban design on aquatic ecosystems in the United States. Pew Oceans Commission, Arlington, VA, 31 pp.

Clarke, K., 1993. Non-parametric multivariate analysis of changes in community structure. Australian Journal of Ecology 18, 117-143.

Crosset, K. M., Culliton, T. J., Wiley, P. C., Goodspeed, T. R., 2004. Population trends along the coastal United States, 1980-2004. National Oceanic and Atmospheric Administration, NOAA National Ocean Service Management and Budget Office Special Projects, $47 \mathrm{pp}$.

Fair, P. A., Adams, J. D., Zolman, E., McCulloch, S. D., Goldstein, J. D., Murdoch, M. E., Varela, R., Hansen, L., Townsend, F., Kucklick, J., Bryan, C., Christopher, S., Pugh, R., Bossart, G. D., 2006. Protocols for conducting dolphin capture-release health assessment studies. US Department of Commerce, NOAA Technical Memorandum NOS NCCOS 49, Silver Spring, MD, 83 pp.

Giesy, J. P., Kannan, K., 2001. Global distribution of perfluorooctane sulfonate in wildlife. Environmental Science and Technology 35, 1339-1342. 
Hekster, F. M., Voogt, P. d., Pijnenburg, A. C. M., Laane, R. W. P. M., 2002.

Perfluoroalkylated substances - Aquatic environmental assessment. Report RIKZ/2002.043, RIKZ, Amsterdam, Netherlands, 99 pp.

Houde, M., Martin, J. W., Letcher, R. J., Solomon, K. R., Muir, D. C. G., 2006a. Biological monitoring of perfluoroalkyl substances: a review. Environmental Science and Technology 40, 3463-2473.

Houde, M., Bujas, T. A. D., Small, J., Wells, R. S., Fair, P. A., Bossart, G. D., Solomon, K. R., Muir, D. C. G., 2006b. Biomagnification of perfluoroalkyl compounds in the bottlenose dolphin (Tursiops truncatus) food web. Environmental Science and Technology 40, 4138-4144.

Houde, M., Wells, R. S., Fair, P. A., Bossart, G. D., Hohn, A. A., Rowles, T. K., Sweeney, J. C., Solomon, K. R., Muir, D. G., 2005. Polyfluoroalkyl compounds in free-ranging bottlenose dolphins (Tursiops truncatus) from the Gulf of Mexico and Atlantic Ocean. Environmental Science and Technology 39, 6591-6598.

Kannan, K., Koistinen, J., Beckmen, K., Evans, T., Gorzelany, J. F., Hansen, K. J., Jones, P. D., Helle, E., Nyman, M., Giesy, J. P., 2001. Accumulation of perfluorooctane sulfonate in marine mammals. Environmental Science and Technology 35, 15931599.

Kannan, K., Corsolini, S., Falandysz, J., Fillmann, G., Kumar, K., Loganathan, B., Mohd, M., Olivero, J., Van Wouwe, N., Yang, J., Aldous, K., 2004.

Perfluorooctanesulfonate and related fluorochemicals in human blood from several countries. Environmental Science and Technology 38, 4489-4495. 
Keller, J. M., Kannan, K., Taniyasu, S., Yamashita, N., Day, R. D., Arendt, M. D., Segars, A. L., Kucklick, J. R., 2005. Perfluorinated compounds in the plasma of loggerhead and Kemp's Ridley sea turtles from the southeastern coast of the United States.

Environmental Science and Technology 39, 9101-9108.

Key, B. D., Howell, R. D., Criddle, C. S., 1997. Fluorinated organics in the biosphere. Environmental Science and Technology 31, 2445-2454.

Kim, S., Kannan, K., 2007. Perfluorinated acids in air, rain, snow, surface runoff, and lakes: relative importance of pathways to contamination of urban lakes. Environmental Science and Technology 41, 8328-8334.

Kissa, E., 1994. Fluorinated surfactants, synthesis, properties, applications. Marcel Dekker, New York, 469 pp.

Lau, C., Anitole, K., Hodes, C., Lai, D., Pfahles-Hutchens, A., Seed, J., 2007. Perfluoroalkyl acids: a review of monitoring and toxicological findings. Toxicological Sciences 99, 366-394.

Litz, J. A., Garrison, L. P., Fieber, L. A., Martinez, A., Contillo, J. P., Kucklick, J. R., 2007. Fine-scale spatial variation of persistent organic pollutants in bottlenose dolphins (Tursiops truncatus) in Biscayne Bay, Florida. Environmental Science and Technology 41, 7222-7228.

Martin, J. W., Smithwick, M. M., Braune, B. M., Hoekstra, P. F., Muir, D. C. G., Mabury, S. A., 2004. Identification of long-chain perfluorinated acids in biota from the canadian arctic. Environmental Science and Technology 38, 373-380. 


\section{ACCEPTED MANUSCRIPT}

Maze, K. S., Würsig, B., 1999. Bottlenose dolphins of San Luis Pass, Texas: Occurrence patterns, site-fidelity, and habitat use (Tursiops truncatus). Aquatic Mammals 25, 91103.

Moon, H., Kannan, K., Choi, M., Choi, H., 2007. Polybrominated diphenyl ethers (PBDEs) in marine sediments from industrialized bays of Korea. Marine Pollution Bulletin 54, $1402-1412$.

Nakata, H., Kannan, K., Nasu, T., Cho, H., Sinclair, E., Takemura, A., 2006. Perfluorinated contaminants in sediments and aquatic organisms collected from shallow water and tidal flat areas of the Ariake Sea, Japan: environmental fate of perfluorooctane sulfonate in aquatic ecosystems. Environmental Science and Technology 40, 49164921.

Organisation for Economic Co-operation and Development, 2007. Lists of PFOS, PFAS, PFOA, PFCA, Related Compounds and Chemicals that may degrade to PFCA (as revised in 2007). Organization for Economic Co-operation and Development, Paris, FR, 157 pp.

So, M. K., Taniyasu, S., Yamashita, N., Giesy, J. P., Zheng, J., Fang, Z., Im, S. H., Lam, P. K. S., 2004. Perfluorinated compounds in coastal waters of Hong Kong, South China, and Korea. Environmental Science and Technology 38, 4056-4063.

Taniyasu, S., Kannan, K., Horii, Y., Hanari, N., Yamashita, N., 2003. A survey of perfluoroocatane sulfonate and related perfluorinated organic compounds in water, fish, birds, and humans from Japan. Environmental Science and Technology 37, 2634-2639. 


\section{ACCEPTED MANUSCRIPT}

United Nations Environment Programme, 2006. Draft risk profile: perfluorooctane sulfonate (PFOS). United Nations Environment Programme, Geneva, CH, 34 pp.

United States Census Bureau, 2007. Table 3. Population change in the 100 fastest-growing metropolitan statistical areas: April 1, 2000 to July 1, 2006. http://www.census.gov/Press-Release/www/releases/archives/cb07-51tbl3.pdf, Date Accessed: July 6, 2007.

United States Environmental Protection Agency, 2000. Perfluorooctyl sulfonates: proposed significant new use rule. Federal Register 65(202), 62319-62333.

Wania, F., 2007. A global mass balance analysis of the source of perfluorocarboxylic acids in the Arctic Ocean. Environmental Science and Technology 41, 4529-4535.

Wilson, B., Thompson, P. M., Hammond, P. S., 1997. Habitat use by bottlenose dolphins: Seasonal distribution and stratified movement patterns in the Moray Firth, Scotland. Journal of Applied Ecology 8, 1365-1374.

Yamashita, N., Kannan, K., Taniyasu, S., Horii, Y., Petrick, G., Gamo, T., 2005. A global survey of perfluorinated acids in oceans. Marine Pollution Bulletin 51, 658-668.

Yamashita, N., Taniyasu, S., Petrick, G., Wei, S., Gamo, T., Lam, P. K. S., Kannan, K., 2007. Perfluorinated acids as novel chemical tracers of global circulation of ocean waters. Chemosphere in press

Zolman, E. S., 2002. Residence patterns of bottlenose dolphins (Tursiops truncatus) in the Stono River estuary, Charleston County, South Carolina, U.S.A. Marine Mammal Science 18, 879-892. 


\section{ACCEPTED MANUSCRIPT}

Fig.1

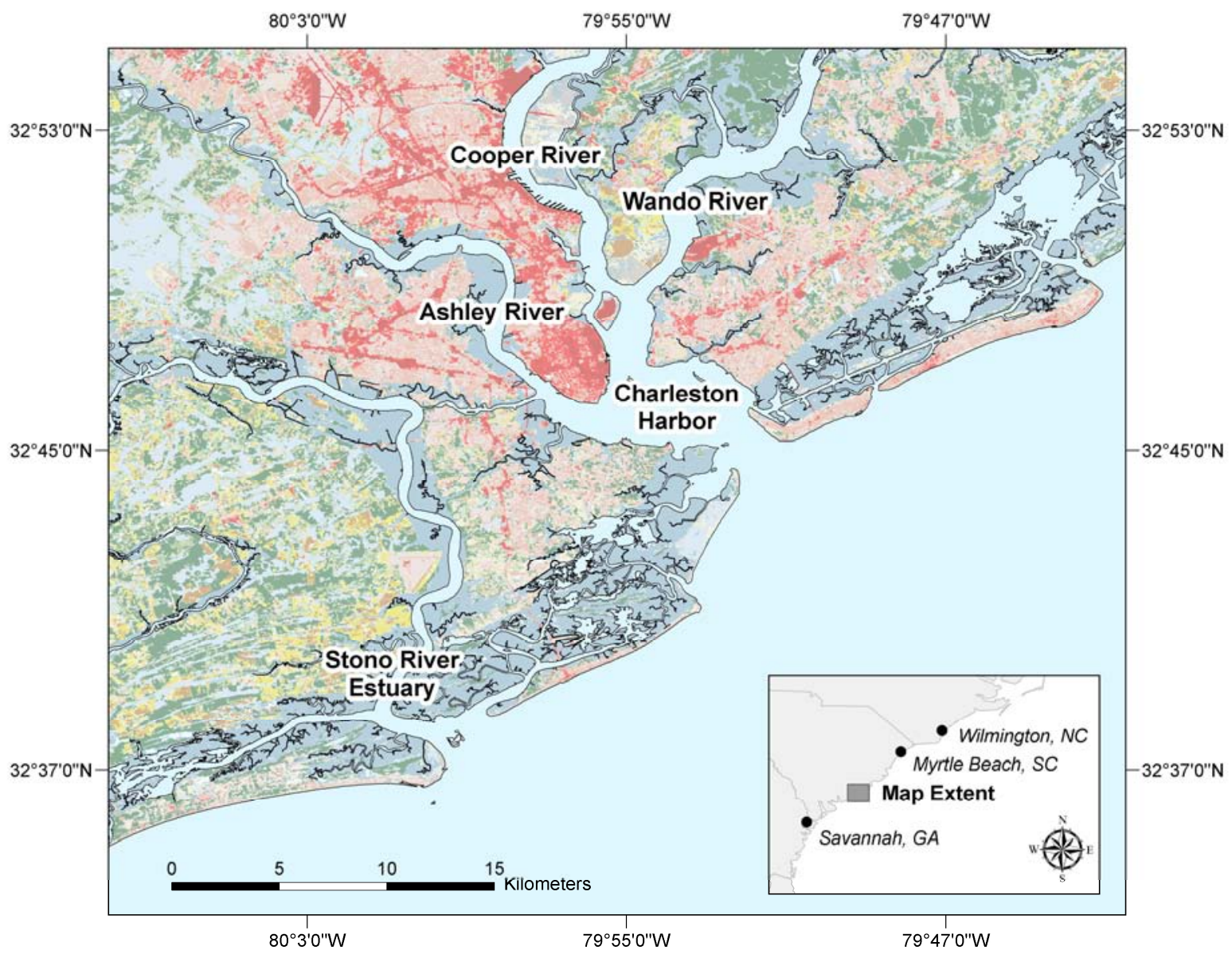




\section{ACCEPTED MANUSCRIPT}

Fig.2

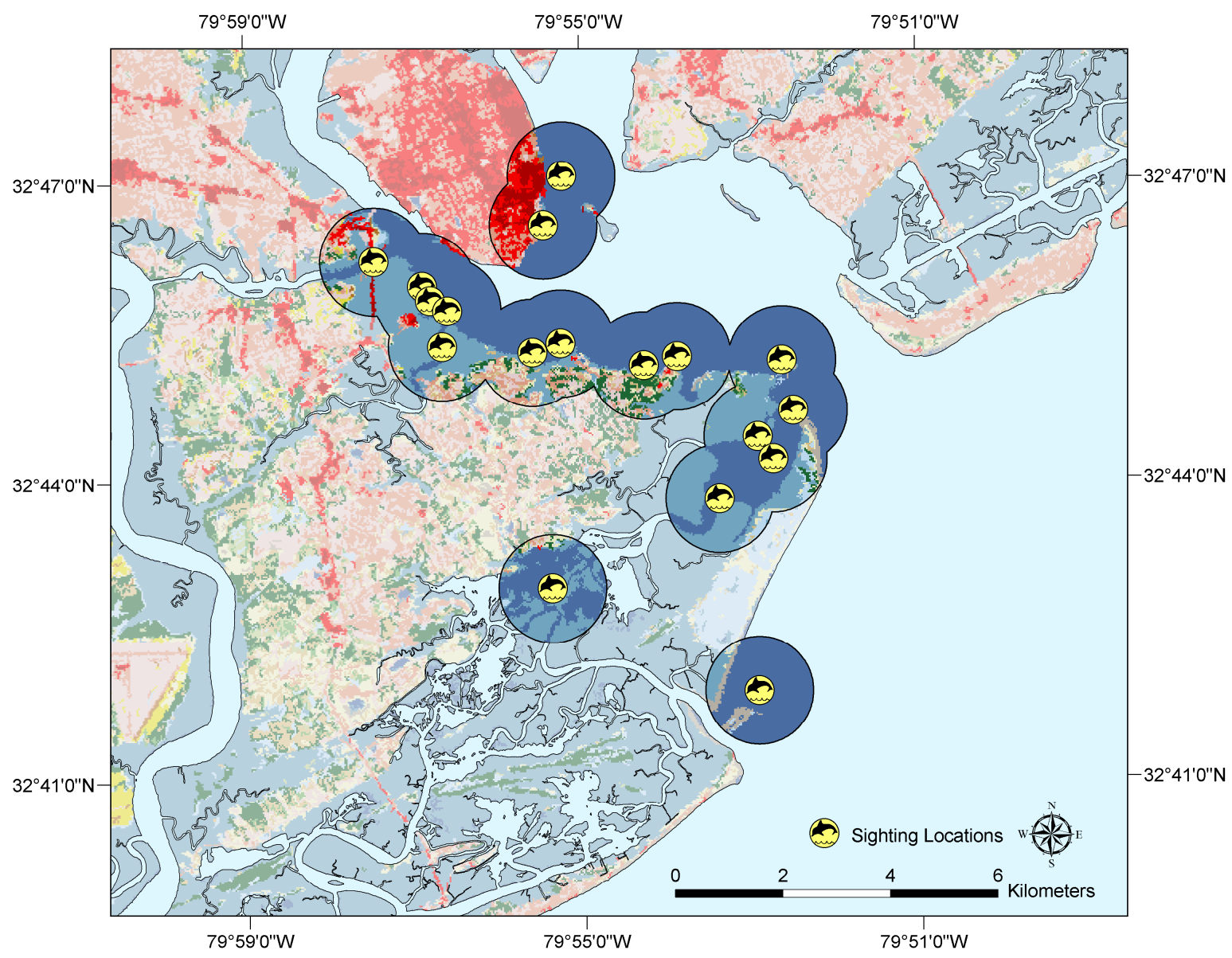


Fig.3

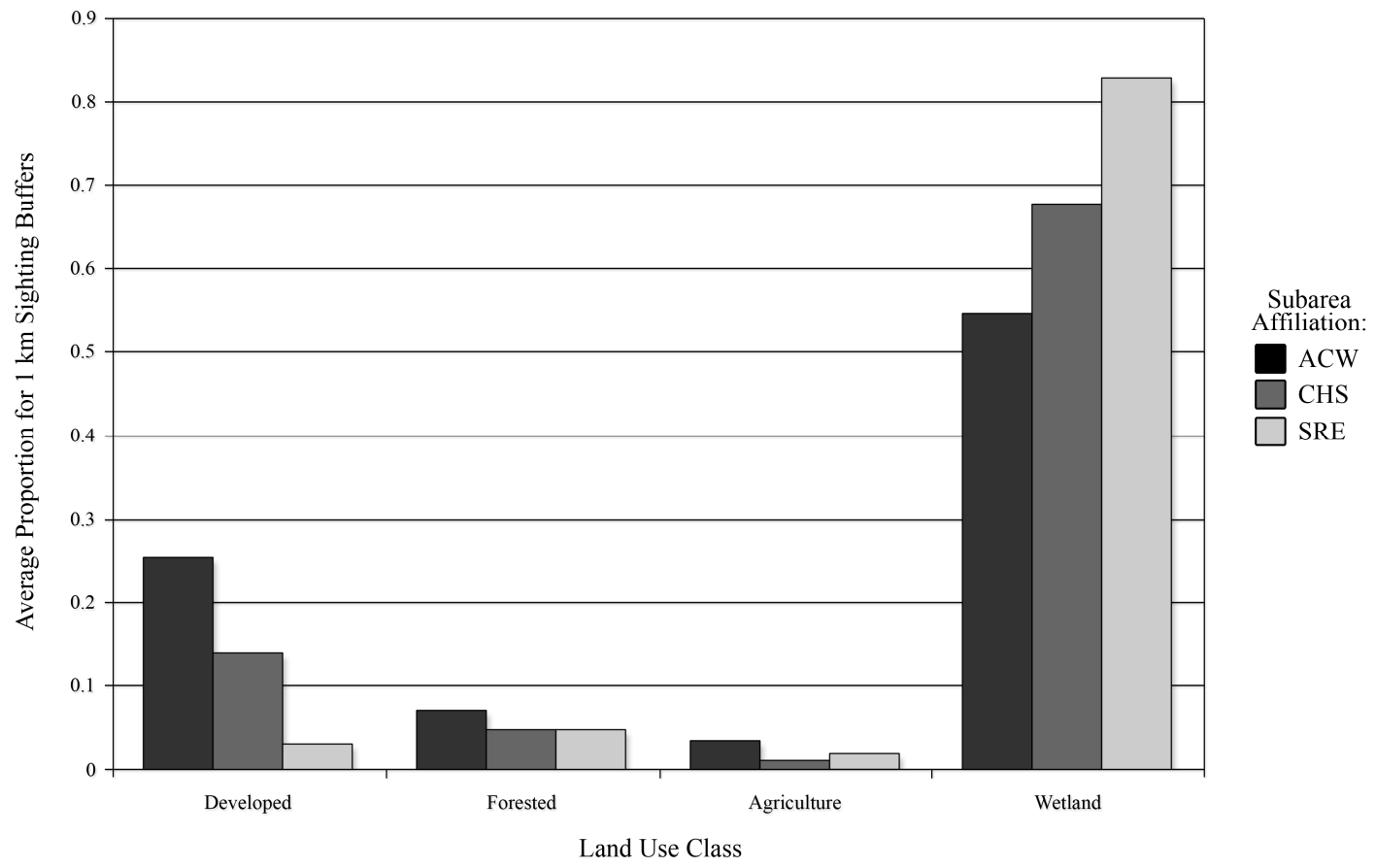




\section{ACCEPTED MANUSCRIPT}

Fig.4

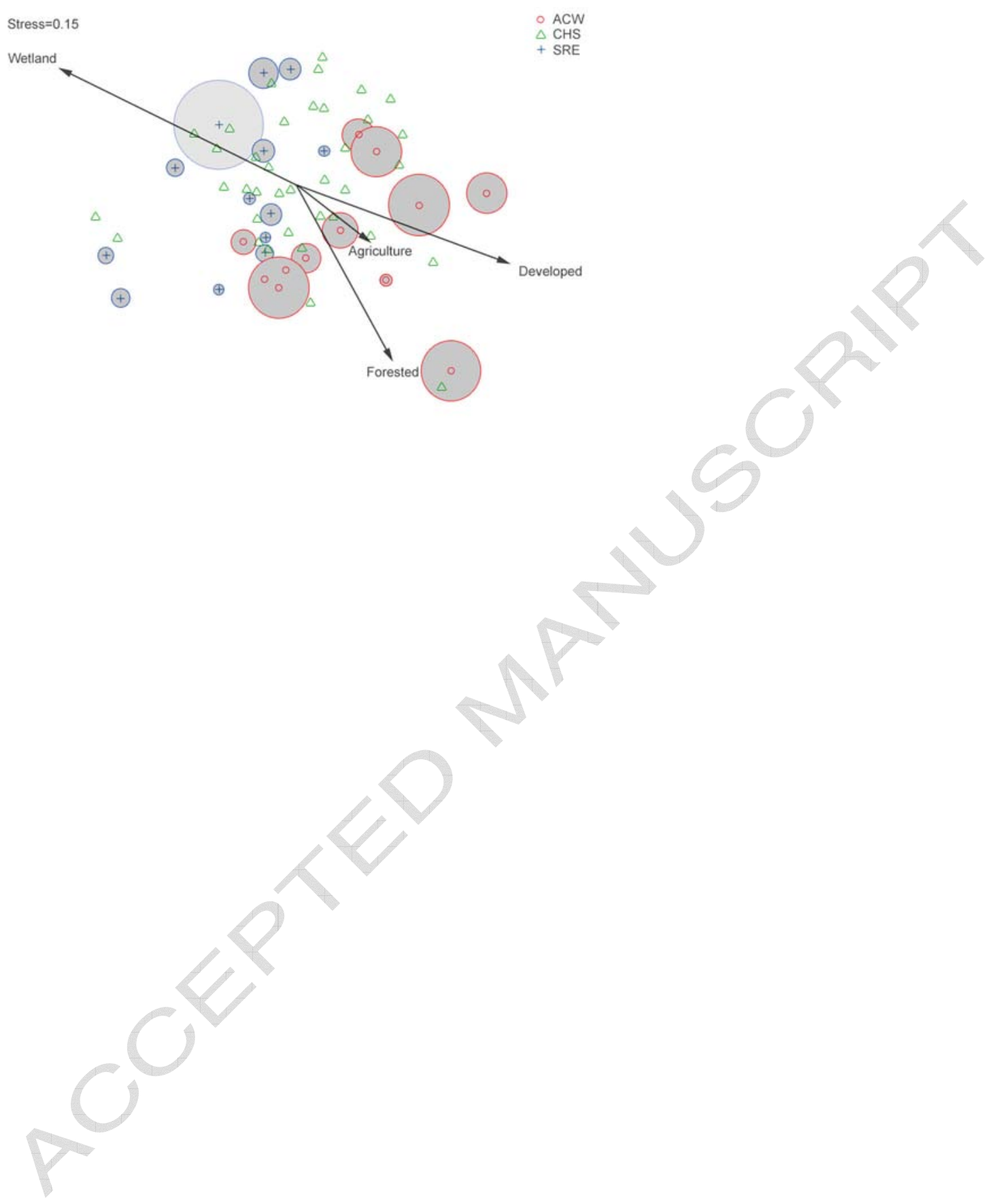

